Available online at www.refaad.com

VMPH 1(3); 2020: 85-90

Research Article

Veterinary Medicine and Public Health Journal (VMPH)

Journal Homepage: https://www.refaad.com/views/vmph/home.aspx

www.refaad.com

ISSN : 2707-7195(Online) 2707-7187(Print)

\title{
Histoarchitecture and histochemical study of the exocrine pancreas of the adult guinea pigs (Cavia porcellus)
}

\author{
F.J. Al-Saffar ${ }^{\text {a* }}$ and Riyadh Hameed Nasif ${ }^{b}$ \\ a Department of Anatomy, College of Veterinary Medicine, University of Baghdad, Baghdad, Iraq \\ ${ }^{b}$ College of Science, University of Diyala, Diyala, Iraq \\ *Corresponding author: F.J. Al-Saffar (assaffar1955@yahoo.com, Fayak1955@gmail.com)
}

How to cite this article: Al-Saffar \& Nasif. Histoarchitecture and histochemical study of the exocrine pancreas of the adult guinea pigs (Cavia porcellus). Veterinary Medicine and Public Health Journal 1(3); 2020:85-90.

DOI: https://doi.org/10.31559/vmph2020.1.3.3

Received Date: 29/4/2020

Accepted Date: 17/6/2020

\begin{abstract}
The pancreas is an organ of special interest from a medical viewpoint as it is the target of two major diseases; diabetes mellitus and pancreatic cancer. The present study was conducted to investigate the histoarchitecture and histochemical aspects of the exocrine portion of the pancreas in the adult male and female guinea pigs. Eight animals of each sex were used to perform the project. Specimens were either fixed using 10\% neutral buffered formalin or Bouin's solution. Tissues sections were stained using different stains such as hematoxylin and eosin (H\&E), Masson's Trichrome (MTC), Periodic acid Schiff (PAS), Alcian blue (AB) (pH 2.5) and a combination of the last two stains. Exocrine portion of the pancreas formed up nearly the whole of the pancreas. It was constructed of different sized lobules of well-formed parenchyma made by densely packed acinar units. The parenchyma provided with well duct system in which most of interlobular ducts were lined by simple columnar epithelium with goblet cells associated with subepithelial mucous glands. The main (minor pancreatic) duct was surrounded by supporting connective tissue which possessed smooth muscle fibers. Unique histological features of the pancreas in Guinea pigs were recorded such as only the wall of minor pancreatic duct having smooth muscle fibers that was supportive to the duct till its entrance the duodenal wall and most branches of the duct system were lined by columnar epithelium with goblet cells reacted positively toward both PAS and AB staining procedures. Autonomic ganglia were detected only in the body lobe adjacent to the large and larger interlobular ducts and vessels in the pancreas.
\end{abstract}

Keywords: pancreas; guinea pig; acini; pancreatic duct; histochemistry.

\section{Introduction}

Pancreas is an organ of special interest from a medical viewpoint as it is the target of two major diseases that are diabetes mellitus and pancreatic cancer. It is to be hoped that a better understanding of the morphology and histology of this organ will eventually contribute to the development of novel therapies for the treatment of either or both of the above diseases (Seymour et al., 2004).

There are imperative roles of the exocrine and endocrine portions of the pancreas to secret many important digestive enzymes as well as some important hormones that play a role in blood sugar metabolism. Therefore, disorders that afflict the pancreas can occur in both portions and research into the structures of the pancreas could provide much insight into the etiology of many of the related diseases (Mastracci and Sussel 2012). Actually, guinea pigs are widely distributed nowadays because of their popularity as a pet and a food source. They were frequently used in biomedical research beside other laboratory species such as rabbits and rats (Mehrez and Mousa 2011; Al-Saffar et al., 2010; Al-Saffar et al., 2009).

Up to date there is no research in the current literatures conducted to describe the histology and histochemistry of the pancreas of the adult guinea pigs and there is paucity of work focused only on the pathological aspect and concerned diseases of this organ in cats, rabbit, dogs, rats and other species (AlSaffar and Al-Zuhairy, 2017; AL-Saffar and Al-Hasnawy, 2014; Gwarzo et al., 2010; Newman et al., 2009; Constautinescu et al., 2006). Accordingly, the current 
project was conducted to study the histoarchitecture and histochemical aspects of the pancreas of adult male and female guinea pigs to provide better understanding data and provides basic scientific information to conduct physiological and pharmaceutical researches

\section{Materials and methods Animals and study design}

Clinically, sixteen healthy adult guinea pigs (8 males and 8 females) were bought from local farms at Diyala province and they were caged in the animal house till their euthanasia and dissection to obtain their pancreases. This research project was conducted from January 2018 to April 2019. Each selected animal was euthanized prior to its dissection by intra-venous injection of over dose of $140 \mathrm{mg} / \mathrm{kg}$ of sodium pentobarbital (Euthasol; Delmarva Laboratories, Midlothian, VA) (Eifler et al., 2009). After that, the animal was dissected on a dissecting board.

\section{Histological techniques}

The representative specimens were cut from each lobe of pancreas for histological approach. A set of specimens were immersed in 10\% neutral buffered formalin for $72 \mathrm{hrs}$ and another set of specimens were fixed using Bouin's solution for 16 hrs for subsequent histochemical processing. Specimens were dehydrated through ascending series of ethyl alcohol (70\%, 80\%, $90 \%$ and $100 \%$ ) each for $2 \mathrm{hrs}$, and then cleared with xylene for $1 / 2 \mathrm{hr}$. Processed specimens were infiltrated that are related to the diseases of pancreas. Certainly, the obtained data will provide good animal model for both veterinary field in animals and public health in human.

with paraffin wax on $58^{\circ} \mathrm{C}$ then embedded with paraffin wax to obtain blocks of paraffin. Sections of $6 \mu \mathrm{m}$ were obtained by using rotary microtome. The sections were stained with either one of the following stains: H\&E, MTC, PAS, AB ( $\mathrm{pH} 2.5$ ) and combined PAS-AB ( $\mathrm{pH} 2.5$ ).

The tissue sections were examined using Olympus light microscope. Sections were photographed and analyzed by Dino-eye piece camera provided with Image software (Insert model, manufacturer and country of origin).

\section{Results}

Gross observations indicated the presence of three irregular lobes (right, body and left) in the pancreas of the studied guinea pigs (Fig. 1). The type of pancreas was compact which was characterized distinctly with gross lobulation. The organ showed minor pancreatic duct only and absence of the major pancreatic duct.

The light microscopy of serially sectioned pancreatic lobes revealed the presence of the following structures: exocrine portion which include capsule, stroma, acini (represent the parenchyma) and associated duct system beside the endocrine portion represented by the Islet's of Langerhans.

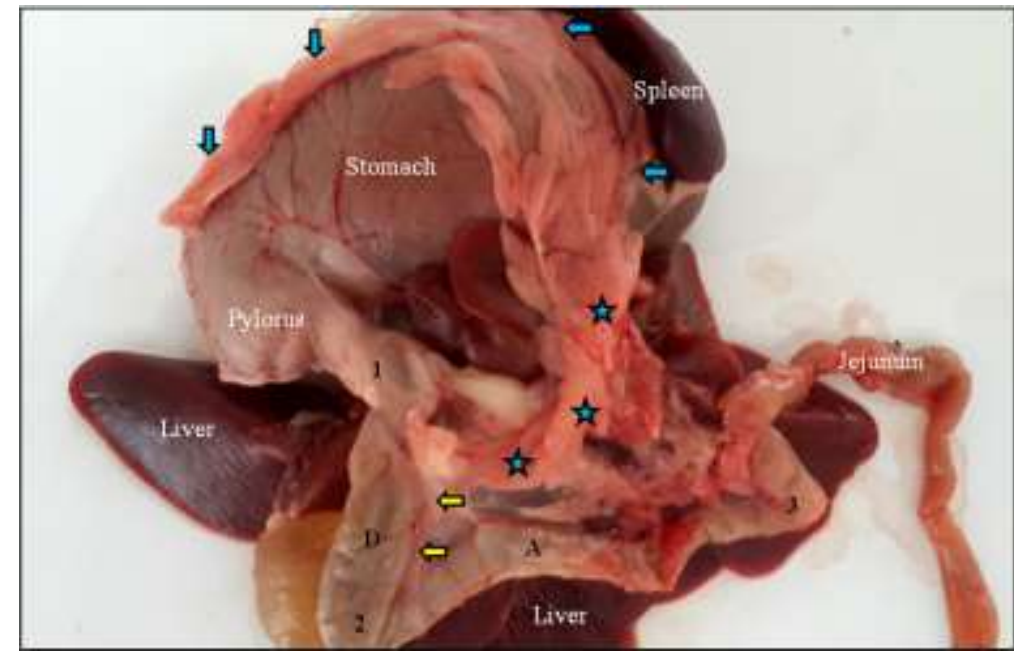

Fig (1): Pancreatic lobes with adjacent organs showing body (blue stars), right lobe (yellow arrows), left lobe (blue arrows). Figure also showed 1st (1), $2^{\text {nd }}$ (2) and $3^{\text {rd }}$ (3) duodenal flexures formed by descending (D) and ascending (A) duodenum.

\section{Capsule and stroma}

Microscopic examination revealed a thin layer of loose connective tissue surround all over the organ. In fact, this was not a true capsule but it was a part of the mesentery which held and fixed the organ in situ. Numerous thin septae of loose connective tissue were extended from this capsule separating many different sized pancreatic lobules (Fig. 2).

The septae or interlobular loose connective tissue fibers were scanty but condensed around the intralobular and interlobular ducts as well as around the accompanied blood vessels. Also, very fine connective tissue observed between the acini of the glandular tissue. The dense connective tissue presents around the ducts and blood vessels easily observed when the sections of pancreas stained with Masson's trichrome stain procedure. Characteristically, fatty tissue was observed in the interlobular septae and single or groups of fat cells were detected in the pancreatic structure, distinctly in female individuals (Fig. 2).

\section{Parenchyma}

The parenchyma of the pancreas was formed by the presence of different sized small structures called the acini. These units were collected together forming numerous lobules that were separated from each other 
by very fine connective tissue septae. Each of which was formed of pyramidal epithelial cells. The cells were characterized by apical zymogene granules with basally located nuclei. The acini of the pancreas were surrounded distinctly by the myoepithelial cells that were characterized by their flattened shaped and darkly stained nuclei (Fig. 2). These cells were peripherally located between the basement membrane and the bases of pyramidal cells. Mostly they were covered one or two of adjacent pyramidal cells. A group of cells were detected around the lumina of the acini. These cells established the first part of the duct system of the exocrine pancreatic portion called centroacinar cells aid to carry out the cellular products of these functional secretory units (Fig. 2).

The microscopic examination showed acini invested in very scanty intralobular loose connective tissue in which blood capillaries, small arterioles and intralobular ducts were present (Fig. 2). The acini which formed the parenchyma were invested by many rounded or oval-shaped structures, the islets of Langerhans. The loose connective tissue with numerous blood capillaries were distinctly observed around these islets and the interlobular blood vessels and ducts. Many fat cells and spots areas of fatty tissue were present embedded in the exocrine portion characteristically in the female pancreas.

Microscopic examination showed well developed duct system in the pancreas of adult guinea pigs. It was

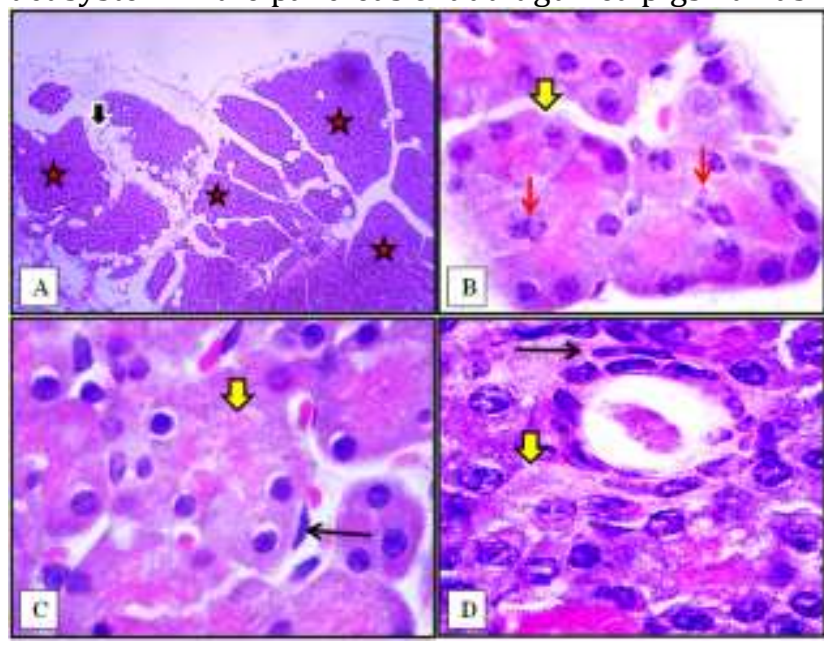

Fig (2): Histological sections of the pancreas of adult guinea pigs. A: different sized pancreatic lobules (red stars) separated by interlobular connective tissue filled with adipose tissue (black arrow). B: centroacinar cells (red arrows) in the pancreatic acini (yellow arrow). C: acini surrounded by myoepithelial cells (black arrow). D:

myoepithelial cell (black arrow) surrounded intercalated duct. H \&E, X4 (A), X40 (B, C, D). begun by the appearance of approximately 1-3 centroacinar cells around the lumina of the pancreatic acini (Fig. 2). These cells subsequently joined the small intercalated ducts which were lined with cuboidal epithelial cells. As mentioned previously for the acini, these ducts were also surrounded by myoepithelial cells (Fig. 2).

The intercalated ducts were connected together to form the intralobular duct lined with simple cuboidal epithelium. The latter ducts left the pancreatic lobules directed toward the interlobular septae where they were still lined with simple cuboidal epithelium. Subsequently, many of these mentioned ducts where converged forming large interlobular ducts lined with simple columnar epithelium with goblet cells (Fig. 2). The connection of many of these ducts formed the larger interlobular ducts characterized by the simple columnar epithelium with goblet cells accompanied with subepithelial connective tissue filled with mucous glands (Fig. 3).

The subepithelial connective tissue condensed and stained positively with Masson's trichrome stain. The collagenous connective tissue fibers were stained green or blue when the light green or aniline blue was used in the preparation of this stain. Distinctly, the connective tissue was densely distributed around the ducts mentioned above as well as the blood vessels (Fig. 2).

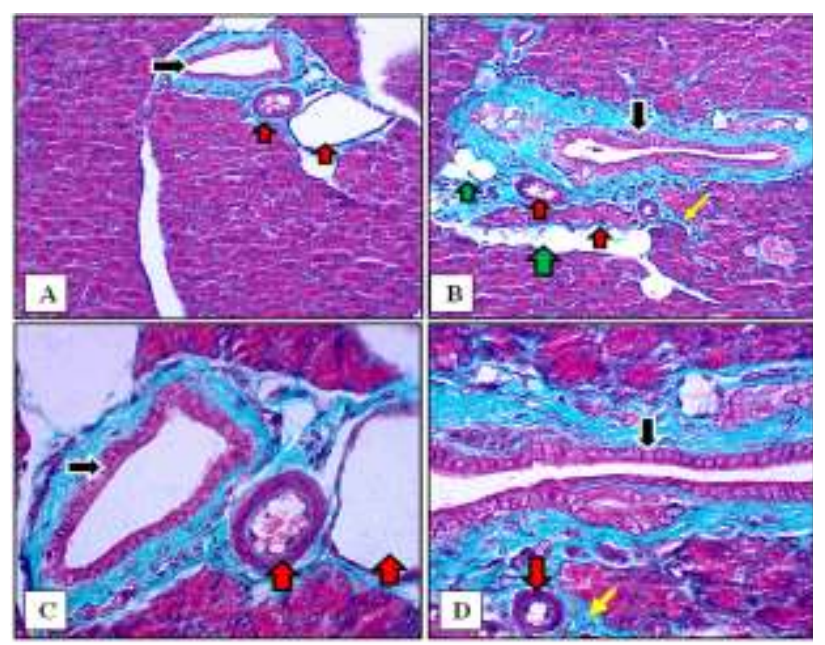

Fig (3: Distribution of connective tissue stroma around blood vessels (red arrows), interlobular ducts (black arrows) with scanty fibers around acini (yellow arrows). Presence fatty tissue (green arrows). MTC, X10 (A \& B), X40 (C \& D).

\section{Duct system}

The described above larger interlobular ducts were observed in the cores of the left and right lobes together with those in the body were converged forming a new duct characterized by thick wall. The duct lined by simple columnar with goblet cells, subepithelial mucous glands with presence of circularly arranged smooth muscle bundles (Fig. 4). This formed duct called minor pancreatic duct. It was the main duct of the pancreas in the studied guinea pigs. It was established in the body and directed toward the last part of ascending duodenum passing through the tissue of the connecting part of the body. Characteristically, the minor pancreatic duct traverses the wall of ascending duodenum obliquely and it precise and passes through 
the wall in between the external and internal muscular layers of the duodenal tunica muscularis. Subsequently, it opened into the duodenal lumen. Histochemically, the mucous of the goblet cells and mucous glands were strongly stained blue with $A B$ (Fig. 6), whereas, moderately or sometime weakly stained pink with PAS (Fig. 5). Post applying combined AB-PAS procedure, mucous of goblet and mucous glands were stained magenta color. As same as the previous ducts, the goblet cells and mucous glands of the minor pancreatic duct were positively stained with histochemical stains such as AB, PAS, and combined AB-PAS stains. The data showed no clear differences in the duct system of the pancreas between male and female individuals.

\section{Pancreatic ganglia}

Many small intramural parasympathetic ganglia were embedded between acini. The ganglion cells were large in size having rounded nuclei and small nucleoli. Their cytoplasm showed prominent Nissl's granules. The ganglion cells were surrounded with many small darkly stained glial cells (Fig. 4).

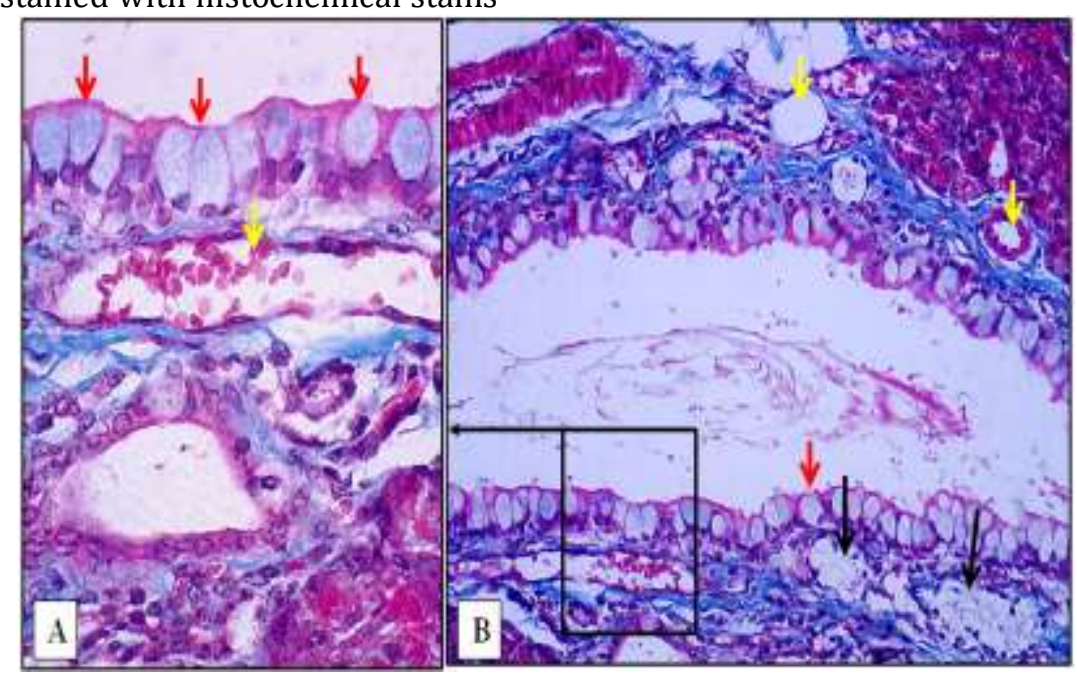

Fig (4): Larger interlobular duct lined with simple columnar epithelium ciliated with goblet cells (red arrows) and subepithelial glands (black arrows), blood vessels (yellow arrows). MTC, X40 (A), X20 (B).

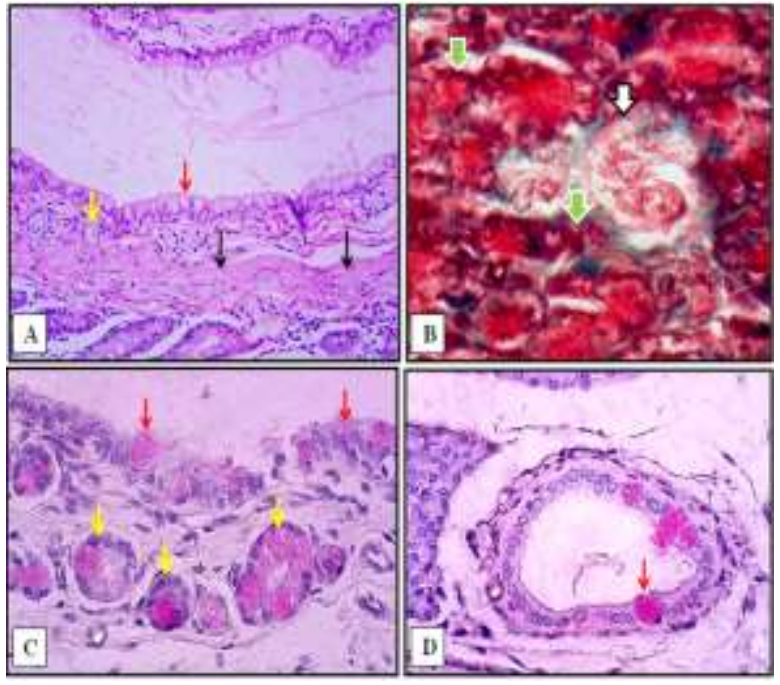

Fig (5): A: Minor pancreatic duct lined with simple columnar epithelium ciliated with goblet cells (red arrows) and subepithelial mucous glands (yellow arrows) surrounded by muscular layer of smooth muscle fibers (black arrows). H\&E, X20. B: parasympathetic ganglion (white arrow) embedded in parenchyma (green arrow). MTC, X40. C \&D: PAS positive reaction of mucin in goblet cells (red arrows) and subepithelial mucous glands (yellow arrows). PAS.
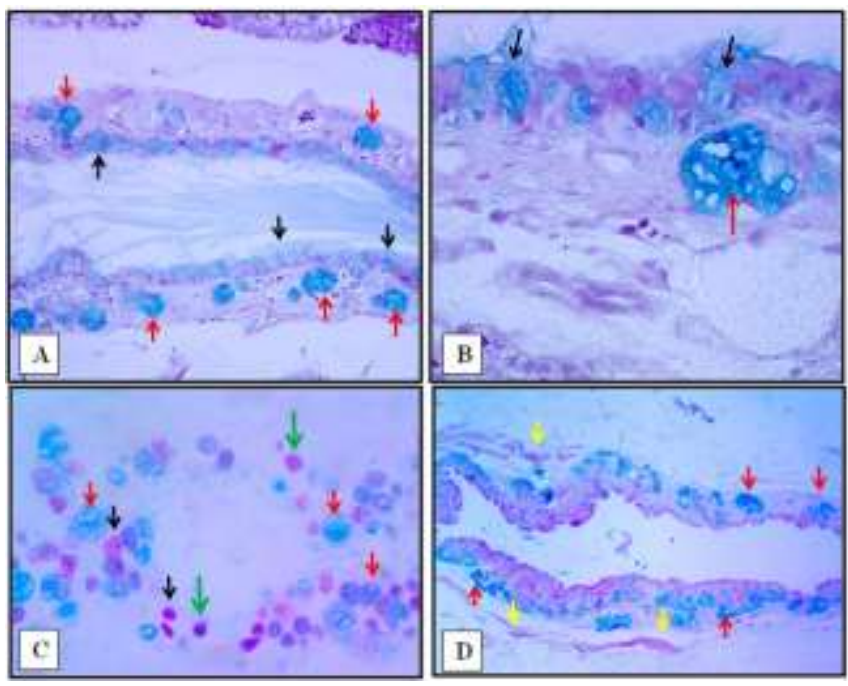

Fig (6): A \& B: AB (pH 2.5) positive reaction of mucin of goblet cells (black arrows) and subepithelial mucous glands (red arrows) in the larger interlobular ducts. X20, X40.

C: Larger interlobular duct stained by combined $\mathrm{AB}$ (pH 2.5)-

$P A S$ showed positive reaction to $A B$ (red arrows) and PAS (black arrows) and combined staining (green arrows). X40. $\mathrm{D}: \mathrm{AB}(\mathrm{pH} 2.5)$ positive reaction of mucin of subepithelial mucous glands (red arrows) in the minor pancreatic duct. Smooth muscle fibers (yellow arrows). X20 


\section{Discussion}

Microscopic findings revealed that the pancreas of adult male and female guinea pigs was a compound tubule-acinar gland formed from both exocrine and endocrine portions. It was subdivided into many different sized pancreatic lobules that were separated by thin loose connective tissue septa. The lobes were formed from densely grouped exocrine units called acini constructed from pyramidal epithelial cells, characterized by apical zymogene granules with basally located nuclei separated from each other by very fine connective tissue septae. Similar observation was previously recorded in other species such as mouse (Houbracken and Bouwens, 2017), cat (Al-Saffar and Al-Zuhairy, 2017) and rat (Fattah, 2008).

In the current study, microscopic examination revealed the presence of myoepithelial cells surrounded the acini units of the pancreas. They appeared peripherally located between the basement membrane and the bases of pyramidal cells. Oppositely, the current findings established the presence of these cells was around the intercalated duct. Similarly, previous investigations have demonstrated these cells were also found around acini in other animals such as local rabbit (AL-Saffar and Al-Hasnawy, 2014). Similarly, to the guinea pig, the pancreas of domestic cat showed myoepithelial cells around the acinar units of the pancreatic parenchyma. They were appeared adherent to the basement membrane of the acini. But differently, the presence of these cells around intercalated ducts in case of guinea pigs was not found in the cat's pancreatic parenchyma (Al-Saffar and AlZuhairy, 2017).

Current findings in the adult guinea pigs showed simple lining epithelium of duct system that was initiated by centroacinar cells and terminated at the minor excretory duct. These microscopic findings were in agreement with those observed in the pancreas of domestic cats, but with some differences such as absence of the goblet cells in the lining epithelium all of the duct system. Moreover, in the cats the wall of the interlobular ducts up to the minor duct showed thin layer of smooth muscle bundles, whereas, in the current student guinea pigs the muscles found only in the minor pancreatic duct (Al-Saffar and Al-Zuhairy, 2016). Similarly, in the domestic rabbits the duct system showed simple epithelium but the goblet cells were observed only in the wall of minor pancreatic duct, as well as lack of the smooth muscle bundles in the wall of this duct different than what was recorded in the guinea pigs (AL-Saffar and Al-Hasnawy, 2014).

Microscopic examination was showed the presence of intramural ganglion positioned inside the pancreatic acinar tissue or as large ganglion closely to the pancreatic lobule. These ganglia were similarly recorded previously in the pancreas of other species such as cats (Al-Saffar and Al-Zuhairy, 2017), rabbits (AL-Saffar and Al-Hasnawy, 2014) and rats (Chumasova etal., 2012).
Current findings did not detect the Pacinian corpuscles in the pancreas of the guinea pigs that were recorded previously in the pancreas of human (GarciaSuarez et al., 2010; Standop et al., 2001) and some mammalian species such as cats (Al-Saffar and AlZuhairy, 2017). So that absence of Pacinian corpuscles in the guinea pig was in agreement with other species such as local rabbits (AL-Saffar and Al-Hasnawy, 2014).

In conclusion, microscopically, autonomic ganglia were detected only in the body lobe adjacent to the large and larger interlobular ducts and vessels in the pancreas of the studied guinea pigs. In addition to that unique histological features were recorded such as only the wall of minor pancreatic duct having smooth muscle fibers that was supportive to the duct till its entrance the duodenal wall and most branches of the duct system were lined by columnar epithelium with goblet cells reacted positively toward both PAS and $A B$ staining procedures.

Acknowledgements: Great respect and many thanks to the Lecturer Dr. Masarat S. Almayahi as she was the professional who assists in staining the histological slides of this research at Anatomy, Histology and Embryology Department of the Veterinary Medicine College / Baghdad University. The authors are greatly appreciated the head of the Department of Anatomy, Histology \& Embryology to provide facilities and support offered to conduct the present project.

Conflict of interest: The authors declare no conflict of interest.

\section{References:}

[1] Al-Saffar, F. J., Ganabadi, S., Yaakub, H. \& Fakurazi, S. (2009). "Collagenase and sodium iodoacetate-induced experimental osteoarthritis model in Sprague Dawley rats". Asian J. Sci. Res. 2(4): 167-179, DOI: 10.3923/ajsr.2009.167.179.

[2] Al-Saffar, F. J. Ganabadi, S. Yaakub, H. Fakurazi, S. \& Lip, M. (2010). "Chondroprotective effect of Zerumbone on monosodium iodoacetate-induced steoarthritis in rats". J. Appl. Sci. 10(4): 248-260, DOI: 10.3923/jas.2010.248.260.

[3] AL-Saffar, F. J. \& Al-Hasnawy A, H. A. (2014). "Histomorphological Developmental Study of Advanced Postnatal of the Pancreas of Local Rabbit". J. Biol. Sci. 14 (6): 387- 402, DOI: 10.3923/jbs.2014.387.402.

[4] Al-Saffar, F. J. \& Al-Zuhairy, M. F. (2016). "Postnatal developmental histomorphological and histochemical study of the duodenum in the domestic cat". Int. J. Curr. Res. 8: 43681-43690.

[5] Al-Saffar, F. J. \& Al-Zuhairy, M. F. (2017)." Postnatal developmental histomorphological and histochemical study of the pancreas in the domestic cat". Int. J. Adv. Res. 5(2): 55-71, https://doi.org/10.21474/ijar01/3115.

[6] Chumasova, E. I. Petrova, E. S. \& Korzhevskii, D. E. (2012). "Distribution and structural organization of the autonomic nervous apparatus in the rat pancreas (an immunohistochemical study)". Neurosci. Behavioral Physiol., 42(8): 781-788, https://doi.org/10.1007/s11055012-9635-6.

[7] Constautinescu, G.M., F.A. Mann \& I.A. Constautinescu. (2006). "Clinical correlations of the biliopancreatic 
Carrefour in dogs and cats". Cercetãri Experimentale \& Medico-Chirurgicale, Anul XIII, 85-91

[8] Eifler, A. C., Lewandowski, R. J., Virmani, S., Chung, J. C., Wang, D., Tang, R. L., Kowalska, B. S., Woloschak, G. E., Yang, G. Y., Robert, K., Ryu, R. K., Salem, R., Larson, A. C., Cheon, E., Strouch, M., Bentrem, D. J. \& Omary, R. A. (2009). "Development of the VX2 pancreatic cancer model in rabbits: A platform to test future interventional radiology therapies". J. Vasc. Interv. Radiol. 20(8): 10751082, https://doi.org/10.1016/j.jvir.2009.04.051.

[9] Fattah, E. A. A. (2008). "Histological and immunohistochemical study of changes in the albino rat pancreas during aging". Egypt J. Histol., 31(2): 266-277.

[10] Garcia-Suarez, O., Calavia, M. G., Perez-Molto, F. J., Alvarez-Abad, C., Perez-Pinera, P., Cobo, J. M. \& Vega, J. A. (2010). "Immunohistochemical profile of human pancreatic Pacinian corpuscles". Pancreas, 39(3): 403410, Doi: 10.1097/MPA.0b013e3181bc0372.

[11] Gwarzo, M.Y., V.A. Nwachuka \& A.O. Lateef. (2010). "Prevention of alloxan induced diabetes mellitus in rats by vitamin a dietary supplementation". Asian J. Anim. Sci. 4(4): 190-196, DOI: 10.3923/ajas.2010.190.196

[12] Houbracken, I. \& Bouwens L. (2017). "Acinar cells in the neonatal pancreas grow by self-duplication and not by neogenesis from duct cells". Scientific Reports. 7(1): 110, https://doi.org/10.1038/s41598-017-12721-9

[13] [13] Mastracci, T. L. \& Sussel, L. (2012). "The endocrine pancreas: insights into development, differentiation and diabetes." WIREs Dev. Biol. 1: 609-628, DOI: 10.1002/wdev.44

[14] Mehrez, A.Z. \& M.R.M. Mousa. (2011). "Growth performance of rabbits fed olive pulp in North Sinai". Asian J. Anim. Sci. 5(5): 317-329, DOI: 10.3923/ajas.2011.317.329

[15] Newman, S.J., J.M. Steiner, K. Woosley, D.A. Williams \& L. Barton. (2006). "Histologic assessment and grading of the exocrine pancreas in the dog". J. Vet. Diagn. Invest. 18(1): 115-118, https://doi.org/10.1177/104063870601800119

[16] Seymour, P. A., Bennett, W. R. \& Jonathan M. W. Slack, J. M. W. (2004). "Fission of pancreatic islets during postnatal growth of the mouse". J. Anat., 204: 103-116, Doi: 10.1111/j.1469-7580.2004. 00265.x

[17] Standop, J., Ulrich, A., Schneider, M. B., Andrén-Sandberg, A. \& Pour, P. M. (2001). "Pacinian corpuscle in the human pancreas". Pancreas, 23(1): 36-39, DOI: 10.1097/00006676200107000-00005 